\title{
Phantom Radicular Pain Treated with Lumbar Microdiscectomy: A Case Report
}

\author{
Orkun KOBAN ${ }^{1}$, Ahmet OGRENCI ${ }^{1}$, Onur YAMAN ${ }^{2}$, Sedat DALBAYRAK ${ }^{1}$
}

${ }^{1}$ Neurospinal Academy, Neurosurgery Clinic, Istanbul, Turkey

${ }^{2}$ Koc University, Department of Neurosurgery, Istanbul, Turkey

\section{ABSTRACT}

Phantom limb pain in amputee patients is not well defined in the literature. Also, there is still no clear information on the definition and treatment of phantom radicular pain, in which amputee patients have radicular pain. This phenomenon, called phantom radiculitis or phantom radiculopathy, has been described in a limited number of cases. If a pathological condition that may cause radicular pain is present in amputee patients, the severity of phantom pain increases. Degenerative disc disease is the most common cause of phantom radicular pain. Spinal injection can be used to control this pain. Surgical treatment can be performed when adequate pain control cannot be achieved. The phantom radicular pain of the patient is expected to improve after surgical or medical treatment. The pain is expected to descend to previous levels if phantom pain was present previously. In this paper, we present and discuss a case of phantom radicular pain in the context of treatment with lumbar microdiscectomy.

KEYWORDS: Phantom radicular pain, Spinal injection, Superimposed pain

\section{INTRODUCTION}

$\mathrm{P}$ hantom pain was first described in the $17^{\text {th }}$ century. It is described as a pain in the amputated segment that feels like there is an extremity in that area. The incidence of phantom pain in amputee patients is about $40-80 \%$. This rate is actually much higher than it is supposed to be. However, the etiology of phantom limb pain superimposed by radicular pain is still unclear. Patients may have disruptions in their treatments at this point. Sciatic reasons should be considered if patients have an increase in phantom limb pain and if there is a new limb pain in patients without phantom pain.

\section{CASE REPORT}

A 56-year-old female patient was amputated under the knee in the left lower limb after a traffic accident 15 years ago (Figure 1). There was phantom pain that the patient had graded as $3 / 10$ according to the visual analogue scale (VAS) score and which had been going on for 10 years. The patient was able to maintain his life with phantom pain and was treated at times with medical treatment. She first presented to our orthopedic outpatient clinic with increasing phantom pain and hip pain in the last 40 days. Then, she was referred to our department. No abnormality was observed during the right extremity examination of the patient. Because of amputation in the left lower extremity, hip flexion extension and abduction were evaluated. The Lasegue test of the patient was positive on the left side. A left foraminal disc herniation at the L4-5 level was detected by lumbar magnetic resonance imaging (MRI) of the patient (Figure 2).

We decided to perform transforaminal steroid injections. The pain quickly recovered after the injection but the patient complained of the same pain about one month later. The transforaminal injection was performed again, but the patient presented 15 days later without benefit from the injection and surgical treatment was planned. Left L4-5 microdiscectomy and foraminotomy were performed. The phantom radicular pain in the amputated segment of the patient decreased to 
the level of the previous phantom pain, and the pain in the hip disappeared totally. The sciatica of the patient was therefore resolved.

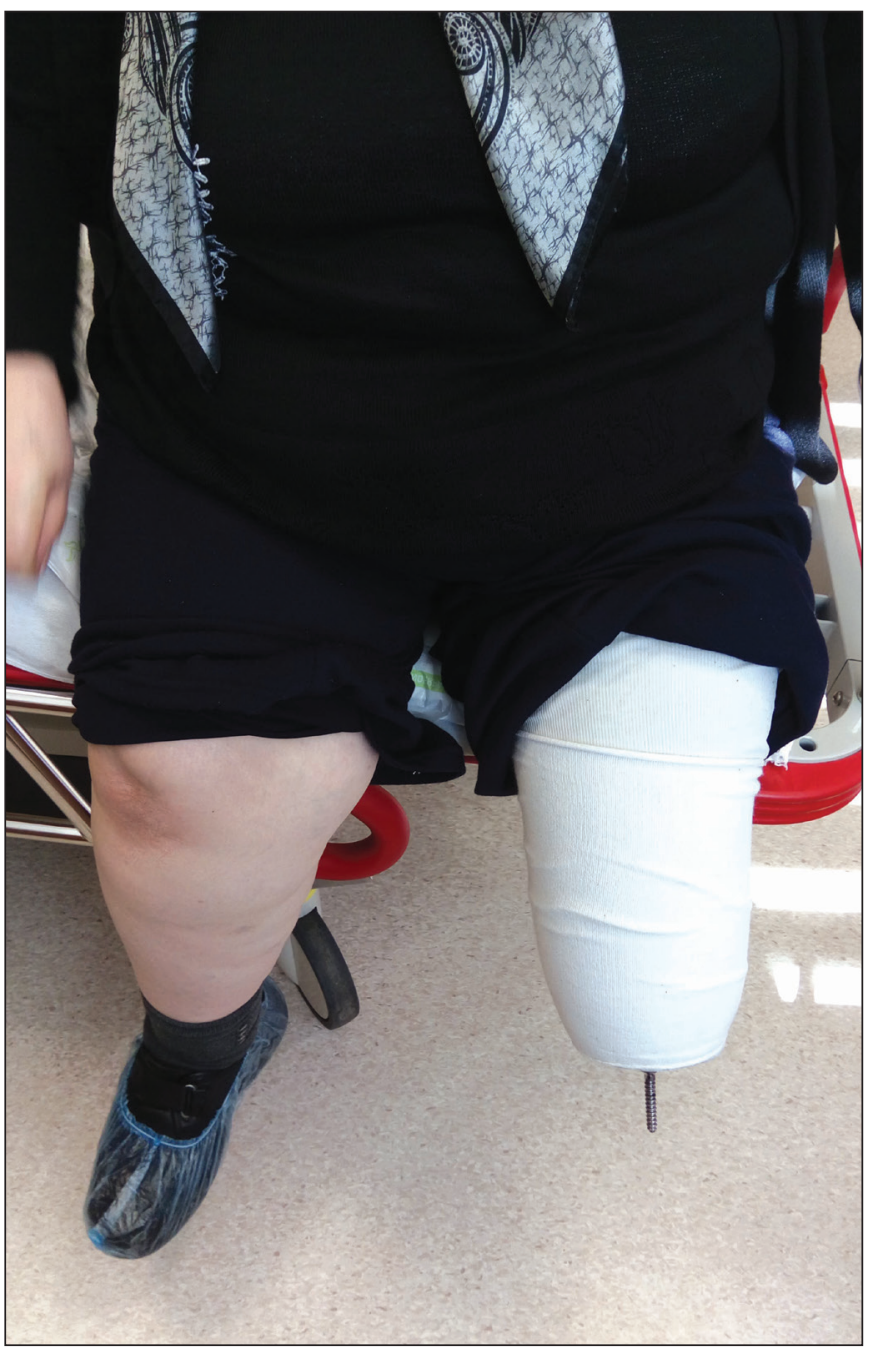

\section{DISCUSSION}

Phantom pain is more common in amputee patients than it is supposed to be $(6,8)$. However, the etiology is still unclear (10). Radicular pain in degenerative disc diseases can be felt in amputee patients as if the amputated leg is present. Croci reviewed the literature and showed that 15 cases were published up to the present (4). This pain, which is added to the phantom pain in the amputated leg, causes more pain to be felt. If there is no phantom pain before, the patient may feel pain in the form of phantom pain on the amputee side for the first time (4). The literature is insufficient to explain the pathophysiology of phantom radiculopathy, but some experts stated that this is felt as a central feeling in the patient's memory $(2,7)$.

If the patient is an under-knee amputee, it can be thought of as phantom radicular pain due to pain both above the knee and in the amputated segment. The pain that is superimposed below the knee can be significant. Lasegue positivity will also help diagnose the degenerative disc disease. If the patient is a more proximal amputee, here Lasegue cannot be evaluated and it is difficult to talk about radicular phantom pain. The most important issue at this point is whether the patient's pain is superimposed. If there is increasing pain, the patient's lumbar region should be examined in detail (1). If a relevant pathological condition is detected on that side, appropriate treatment should be started.

The most effective treatments are injections in order to get faster clinical results and accurate diagnosis (transforaminal, interlaminar, etc.) $(3,5,9)$. Here, radiculopathy-induced pain can be significantly reduced with steroids by decreasing inflammation. Steroids inhibit the production of inflammatory mediators by inhibiting the phospholipase A2 enzyme (11).

Phantom radiculopathy is diagnosed if the patient benefits from injections that were applied to the level(s) considered problematic. The patient is followed and injections can be repeated if needed.

Figure 1: The patient's amputated left leg under knee.
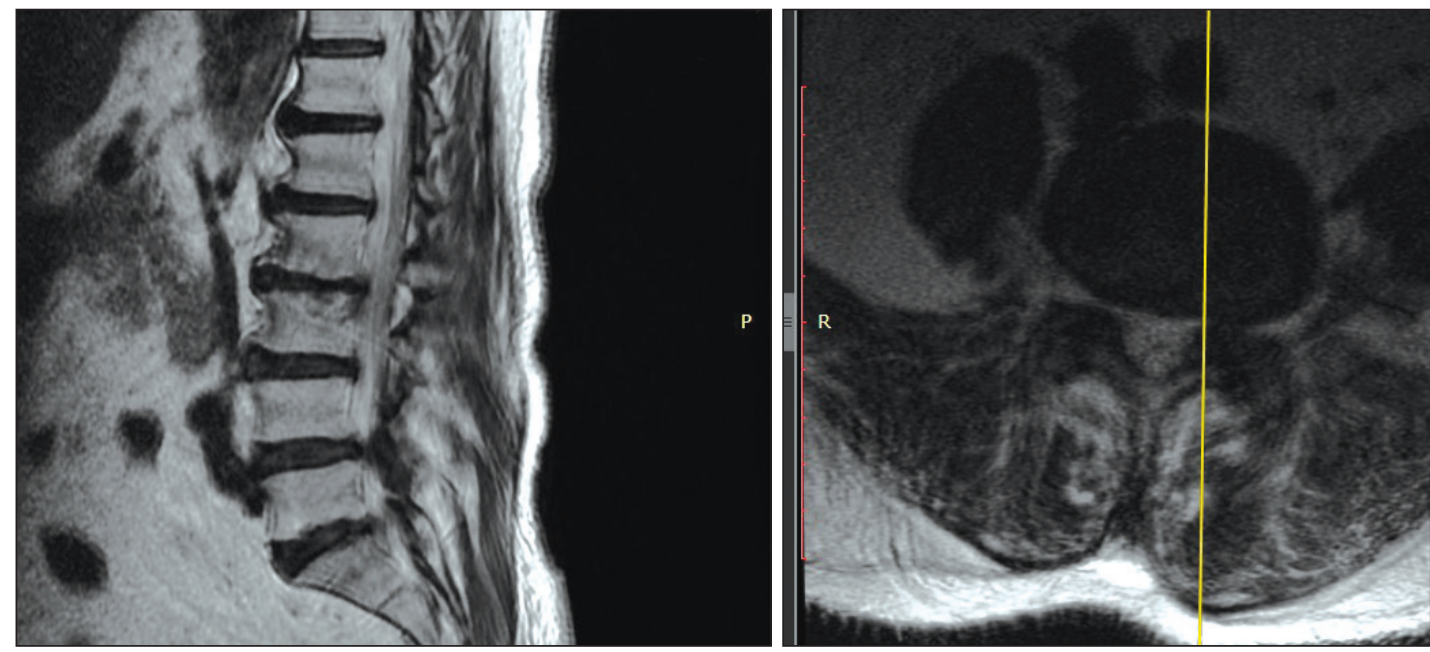

Figure 2: T2W sagittal (left) and axial (right) MRI scans of the patient. Left foraminal disc herniation is seen at L4-5 level. 
As a matter of fact, we also performed transforaminal steroid injections in our case, and there was significant relief in the patient's phantom radicular pain for 1 month. At the follow-up period, we repeated the injection, but the relaxation period was shorter after this procedure. Approximately 15 days later, the patient re-presented with a VAS score of 10 and she underwent left L4-5 microdiscectomy and L5 foraminotomy. The pain was relieved at the thigh, and the pain in the amputated segment decreased to the previous level. The pain at the postoperative 6 months was at a tolerable level with analgesics and supportive care.

Surgically treated phantom radiculopathy is very rare in the literature. Treatment with injections is generally sufficient for pain control. However, standard surgical treatment can be used when the radicular pain continues,

\section{CONCLUSION}

Phantom radicular pain is very rare. The pain in the leg may be in the form of superimposed leg pain and also new onset phantom pain. Injections can be made as initial treatment. In most of the cases, this provides pain control without further intervention. However, in cases where pain control cannot be achieved, or if there is a pathology causing the phantom radicular pain, it should be surgically treated and it can be said that it is very effective.

\section{REFERENCES}

1. Aydin SM, Zou SP, Varlotta G, Gharibo C: Successful treatment of phantom radiculopathy with fluoroscopic epidural steroid injections. Pain Med 6(3): 266-268, 2005
2. Brugger P, Kollias S, Muris R, Crelier G, Hepp-Reymond M, Regard M: Beyond re-membering: Phantom sensations of congenitally absent limbs. Proc Natl Acad Sci 97(11):61676172,2000

3. Buenaventura RM, Datta S, Abdi S, Smith HS: Systematic review of therapeutic lumbar transforaminal epidural steroid injections. Pain Physician 12: 233-251, 2009

4. Croci D, Javier F, Serge M: Phantom radiculopathy: Case report and review of the literature. World Neurosurg 90:19-23, 699, 2016

5. DeGregoris G, Diwan S: Phantom radiculitis effectively treated by fluoroscopically guided transforaminal epidural steroid injections. Pain Physician 13: 505-508, 2010

6. Dijkstra PA, Geertzen JHB, Stewart R, van der Schans CP: Phantom pain and risk factors: A multivariate analysis. J Pain Symptom Manage 24(6): 578-585, 2002

7. Finnoff J: Differentiation and treatment of phantom sensation, phantom pain, and residual limb pain. J Am Podiatr Med Assoc 91: 23-33, 2001

8. Flor $\mathrm{H}$ : Phantom-limb pain: Characteristics, causes, and treatment. Lancet Neurol 1(3): 182-189, 2002

9. Manchikanti L, Singh V, Falco FJE, Cash KA, Pampati V: Evaluation of the effectiveness of lumbar interlaminar epidural injections in managing chronic pain of lumbar disc herniation or radiculitis: A randomized, double-blind, controlled trial. Pain Physician 13(4): 343-355, 2010

10. Sonmez E, Yılmaz C, Caner H, Altinors N: Lumbar disc herniation as a rare cause of stump pain. Case report. J Neurosurg Spine 8(4):398-399, 2008

11. Spaccarelli KC: Lumbar and caudal epidural corticosteroid injections. Mayo Clin Proc 71(2):169-178, 1996 